\title{
MEMETAKAN LEARNING AGILITY PADA PERUSAHAAN SWASTA DI DKI JAYA: APAKAH ONLINE LEARNING, GRIT, DAN COLLABORATIVE SKILL CUKUP BERDAMPAK?
}

\author{
Lovis Ardiyanto ${ }^{1)}$, Nopriadi Saputra ${ }^{2)}$, Richkho Efendi $^{3)}$, Winson Yoe ${ }^{4)}$ \\ ${ }_{1,2,3,4}$ BINUS Business School, Universitas Bina Nusantara, Jakarta \\ winson.yoe@,binus.ac.id
}

\begin{abstract}
The research explored the description of learning agility and the effect of each independent variable, namely online learning, grit, and collaborative skill on learning agility of millennial employees in DKI Jaya. This quantitative research applied an associative approach with data collected through questionnaires with a total of 387 millennial employees in DKI Jaya. This research suggested that millennial employees in DKI Jaya performed good learning agility, online learning, grit, and collaborative skill. Using simple regression analysis, it was known that online learning and collaborative skill each had significant effect on learning agility, while grit was found not to have significant effect on learning agility of millennial employees in DKI Jaya. By this research, the institutions were supposed to continuously support the development of learning agility, online learning, grit, and collaborative skill of millennial employees in DKI Jaya for the sustainability of the institutions.
\end{abstract}

Keywords: Learning Agility, Online Learning, Grit, Collaborative Skill, Millennial

\section{PENDAhuluan}

Sumber daya manusia adalah salah satu faktor yang sangat penting bahkan tidak dapat dilepaskan dari sebuah organisasi, baik instansi maupun perusahaan (Hamid, 2020). Terkait sumber daya manusia, tenaga kerja di Indonesia saat ini sebagian besar diisi oleh generasi milenial, yang mana menurut Badan Pusat Statistik dan Kementerian Pemberdayaan Perempuan dan Perlindungan Anak (dalam Budiati et al., 2018) merupakan generasi dengan individu yang dilahirkan pada rentang tahun 1980-2000 (individu dengan usia 21-41 tahun). Salah satu ciri utama generasi milenial ditandai dengan lebih akrabnya dengan komunikasi, media, dan teknologi digital. Oleh karena dilahirkan dan dibesarkan dengan kecanggihan teknologi, maka generasi milenial memiliki karakteristik seperti berpikir kreatif, selalu terbaharui oleh informasi, mempunyai minat, produktif, serta memiliki pola pikir yang lebih terbuka.

Sejatinya, dengan mengetahui cara yang tepat untuk mengembangkan pegawai milenial, maka perusahaan akan semakin mudah dalam mencapai visi dan misinya, terlebih lagi dalam menghadapi era sekarang di mana perubahan dan dinamika dalam dunia kerja terjadi dengan cepat dan tidak terduga dapat menciptakan gejolak dalam dunia kerja yang lebih dikenal dengan istilah volatility (Zulfikar, 2019). Volatility sendiri merupakan salah satu bagian dari VUCA. Menurut Imperatori (2017), dunia VUCA mempengaruhi hubungan antara perusahaan dan karyawannya. Perusahaan yang menghadapi berbagai tantangan berat mengharapkan karyawan untuk melakukan upaya dan inovasi ekstra sementara karyawan juga mencari keamanan dan stabilitas pekerjaan, mengharapkan keseimbangan kehidupan kerja, dan kebebasan untuk mengejar karir mereka di organisasi lain. 
Oleh karenanya, dalam menghadapi VUCA, diperlukan kemampuan agility atau ketangkasan dalam pola pikir dan kebiasaan, termasuk kemampuan individu untuk menggunakan pengalaman yang dimiliki dalam menyelesaikan permasalahan yang dihadapi dengan cepat meskipun berada dalam kondisi minimnya informasi yang diakses dan prosedur yang kurang jelas, yaitu learning agility atau ketangkasan belajar (Sudirgo, 2020). Learning agility menjadi penting untuk menjaga keberlangsungan perusahaan. Tanpa adanya learning agility, pegawai milenial tidak dapat beradaptasi dengan perkembangan dunia sehingga dapat mempengaruhi keberlangsungan perusahaan tempat mereka bekerja (Saputra et al., 2018).

Selain tantangan era VUCA, terdapat juga tantangan yang sekarang sedang dihadapi oleh dunia yaitu era digitalisasi. Era digital atau Revolusi Industri 4.0 tentunya telah memberikan dampak dalam sistem pembelajaran dengan paradigma baru untuk memajukan sumber daya manusia (Husnussaadah, 2021). Digitalisasi merupakan era dimana sesuatu yang berbentuk non-digital dikonversi menjadi digital, termasuk di antaranya pemanfaatan aplikasi-aplikasi dan fitur-fitur yang dapat mempermudah segala aspek aktivitas sehari-hari (Heiskala et al., 2016). Apalagi semenjak pandemi COVID-19 pada awal tahun 2020 membuat segala aktivitas dilaksanakan secara daring, termasuk kegiatan pembelajaran oleh perusahaan yang kemudian dikenal dengan online learning. Penelitian dari (Ghosh, Muduli, dan Pingle (2021) yang dilakukan kepada 776 orang eksekutif di India menunjukkan bahwa penggunaan online learning dapat memfasilitasi efektivitas learning agility yang lebih baik dengan memungkinkan para peserta untuk mendapatkan pengetahuan dan keahlian baru sesuai dengan kebutuhan belajar mereka.

Learning agility juga dapat dihubungkan dengan grit, yang menurut Duckworth (2016) adalah semangat dan ketekunan untuk tujuan jangka panjang. Menurut Duckworth, Peterson, Matthews, dan Kelly, (2007), grit memerlukan kerja keras dalam menghadapi tantangan selama bertahun-tahun meskipun kegagalan dan kesulitan sedang berlangsung. Salah satu bentuk grit adalah dengan disiplin setiap hari untuk mencoba melakukan hal-hal yang lebih baik daripada yang kita lakukan kemarin (Duckworth, 2016). Dalam hubungannya dengan learning agility, O’Shea (2016) menuturkan bahwa seseorang yang agile cenderung akan memiliki keberanian untuk bertahan bahkan ketika mereka menghadapi rintangan yang tak terhindarkan sehingga dapat disimpulkan bahwa seseorang yang memiliki grit yang tinggi maka akan semakin cepat juga kecepatan dan ketangkasan belajarnya.

Kemampuan learning agility juga dapat dihubungkan dengan kemampuan kolaborasi atau collaborative skill (Aliyyah \& Idham, 2020; Supiyanti, 2019). Collaborative skill adalah suatu proses dimana pihak-pihak dengan keahlian yang berbeda dapat memandang dan mengeksplorasi aspekaspek berbeda dari suatu permasalahan, serta menemukan solusi baru untuk permasalahanpermasalahan tersebut yang akan lebih sulit untuk dipecahkan tanpa hadirnya perspektif dari orang lain (Gray, 1989). Dalam meningkatkan kemampuan learning agility pegawai, collaborative skill harus tercipta di lingkungan kerja. Kemampuan untuk berkolaborasi dianggap sebagai inti penting dalam proses pembelajaran karena pembelajaran difasilitasi ketika seseorang harus berinteraksi satu 
sama lain dan bertukar ide untuk berbagi informasi. Oleh karena itu, meningkatkan keterampilan kolaborasi sangat penting dalam pembelajaran yang efektif yang menunjang munculnya learning agility. Selain itu, keterampilan kolaborasi individu harus dikembangkan, karena individu sering diminta untuk bekerja sama dalam kelompok sebagai bagian dari persiapan mereka dalam menghadapi era globalisasi abad ke-21 (Aini et al., 2020).

Menilik pada penjabaran latar belakang di atas, maka penelitian ini menjadi penting untuk dilakukan karena learning agility berpotensi membantu pegawai milenial untuk belajar lebih baik dan lebih cepat serta lebih termotivasi untuk mendapatkan hasil kerja yang lebih optimal untuk menghadapi masa VUCA dan era digitalisasi. Oleh karena itu, peneliti melakukan penelitian pada skripsi ini yang bertajuk "Memetakan Learning Agility pada Perusahaan Swasta di DKI Jaya: Apakah Online Learning, Grit, dan Collaborative Skill Cukup Berdampak?” dengan tujuan untuk mengetahui gambaran Learning Agility, Online Learning, Grit, dan Collaborative Skill pada pegawai milenial DKI Jaya dan menguji pengaruh dari masing-masing variabel independen, yakni Online Learning, Grit, dan Collaborative Skill terhadap Learning Agility pegawai milenial DKI Jaya.

\section{KAJIAN LITERATUR}

Pada bagian ini peneliti akan menjelaskan lebih dalam mengenai Learning Agility, Online Learning, Grit, dan Collaborative Skill berdasarkan penelitian terdahulu yang relevan.

\section{Learning Agility}

Learning agility adalah kemauan dan kemampuan dari individu untuk mempelajari kompetensi baru di bawah kondisi yang ia alami pertama kali, tangguh, dan berbeda (Lombardo \& Eichinger, 2000). Learning agility berkaitan dengan kemampuan beradaptasi dan keinginan untuk menghadapi hal yang tidak diketahui, dan learning agility mencoba untuk memprediksi kinerja potensial dari individu dalam tugas-tugas baru (Gravett \& Caldwell, 2016). Dari berbagai pengertian di atas, kemudian dapat disimpulkan bahwa learning agility adalah kemampuan individu untuk mempelajari kompetensi baru di bawah kondisi yang ia alami pertama kali, tangguh, dan berbeda yang ditunjukkan dengan kemampuan untuk belajar dengan orang lain, orientasi hasil, pemecahan masalah, dan suka bereksperimen.

Individu dengan learning agility yang tinggi cenderung mencari tantangan baru, aktif mencari umpan balik dari orang lain sebagai bahan refleksi diri dan belajar dari pengalaman untuk diterapkan dalam situasi yang baru (de Meuse et al., 2010; Gravett \& Caldwell, 2016). Lanjut menurut Gravett dan Caldwell (2016) kembali, learning agility penting menjadi salah satu fokus utama dalam perusahaan karena karyawan yang memiliki learning agility dapat memastikan ketangkasan perusahaan dengan mengembangkan proses dan sistem yang lebih baik. Selain itu, mereka juga dapat membantu memastikan bahwa ketangkasan tersebut disebarkan ke karyawan lain dalam perusahaan 
dengan menanamkan budaya learning agility tersebut. Oleh karena itu, learning agility dapat berkontribusi membentuk perusahaan yang berkinerja tinggi dan berumur panjang.

\section{Online Learning}

Online learning (atau e-learning, mobile learning, digital learning, web-based learning, dll.) adalah pengalaman transfer pengetahuan menggunakan video, audio, gambar, komunikasi teks, perangkat lunak, dan dengan dukungan jaringan internet (Basilaia \& Kvavadze, 2020). Online learning, atau oleh MoLeNET (2007) disebut sebagai mobile learning juga adalah eksploitasi teknologi genggam di mana-mana, bersama dengan jaringan nirkabel dan ponsel, untuk memfasilitasi, mendukung, meningkatkan dan melanjutkan jangkauan pengajaran dan pembelajaran. Teo (2010) mendefinisikan online learning sebagai penelitian penggunaan internet oleh pengguna untuk mempelajari konten tertentu. Maka, berdasarkan definisi-definisi yang telah disampaikan, dapat disimpulkan bahwa online learning merupakan suatu sistem pembelajaran yang menggunakan teknologi internet, mobile, maupun teknologi pendukung lainnya untuk menyelenggarakan proses pembelajaran, menciptakan konten baik yang berupa video, audio, maupun teks serta untuk mengatur pembelajaran secara menyeluruh dalam suatu organisasi.

Menurut Noe (2017), terdapat tiga karakteristik penting dalam pembelajaran online learning yaitu: (1) Online learning berkaitan dengan jaringan elektronik yang memungkinkan informasi dan instruksi disampaikan. (2) Online learning disampaikan pada peserta dengan menggunakan komputer dengan teknologi internet. (3) Pada solusi pembelajaran yang melebihi pelatihan tradisional termasuk penyampaian informasi dan alat untuk meningkatkan kinerja.

\section{Grit}

Grit adalah ketekunan dan semangat untuk tujuan jangka panjang (Chen \& Lin, 2019; Duckworth et al., 2007). Grit melibatkan kerja keras menuju tantangan, mempertahankan usaha dan minat selama bertahun-tahun meskipun kegagalan, kesulitan, dan tidak adanya perkembangan sedang berlangsung. Menurut Duckworth, Peterson, Matthews, dan Kelly, (2007), grit memerlukan kerja keras dalam menghadapi tantangan selama bertahun-tahun meskipun kegagalan dan kesulitan sedang berlangsung. Salah satu bentuk grit adalah dengan disiplin setiap hari untuk mencoba melakukan hal-hal yang lebih baik daripada yang kita lakukan kemarin (Duckworth, 2016). Maka, berdasarkan definisi-definisi yang telah disampaikan, dapat disimpulkan bahwa grit merupakan semangat dan ketekunan yang dilakukan untuk mencapai tujuan dan kesuksesan jangka panjang.

Zhang dan Jiang (2019) menuturkan bahwa individu dengan grit tinggi akan melihat proses untuk mencapai tujuan seperti maraton. Ketika terdapat kekecewaan dan kebosanan, maka individu dengan grit tinggi akan memilih untuk tetap berpegang teguh pada tujuannya, sebaliknya, individu dengan grit rendah akan memilih untuk menyerah atau berpaling ke hal lain. Individu dengan grit akan berusaha untuk terus meningkatkan dirinya dan mengumpulkan sumber daya untuk mencapai tujuan 
besar yang menantang dalam hidup, meskipun mendapatkan imbalan yang tidak seimbang. Individu dengan grit tinggi juga cenderung memiliki perspektif yang lebih luas dan jauh, penilaian yang lebih makroskopis terhadap diri mereka sendiri dan lingkungan, arah motivasi yang lebih kuat, kemampuan pengumpulan dan analisis data yang lebih kuat, serta kemampuan berpikir dan bertindak yang lebih sistematis.

\section{Collaborative Skill}

Collaborative skill adalah kemampuan untuk berkolaborasi atau bekerja sama dengan banyak pihak, di mana pun, kapan pun, dan dengan siapa pun (Harman \& Stein, 2015). Collaborative skill juga diartikan sebagai kemampuan individu untuk dapat berinteraksi dan bekerja secara efektif dengan orang lain dalam satu tim, mampu berpartisipasi secara aktif, membimbing serta bertanggung jawab terhadap sesama (Binkley et al., 2011). Berdasarkan definisi-definisi di atas, maka collaborative skill dapat disimpulkan sebagai suatu kemampuan individu untuk dapat berinteraksi dan bekerja secara efektif dengan orang lain dalam satu tim, mampu berpartisipasi secara aktif, membimbing serta bertanggung jawab terhadap sesama.

Individu dengan collaborative skill yang baik cenderung lebih terbiasa untuk berinteraksi dengan orang lain yang beragam untuk dapat berkomunikasi dengan efektif (Aliyyah \& Idham, 2020). Hal tersebut dipertajam kembali oleh penelitian dari Tang, Zheng, Sun, dan Huang (2021) bahwa individu yang memiliki kemampuan kolaborasi yang baik dapat berhasil untuk bekerja sama dengan orang lain dan mempertahankan sikap positif untuk mengurangi konflik antar pribadi dan mencapai tujuan akhir bersama.

\section{Kerangka Berpikir}

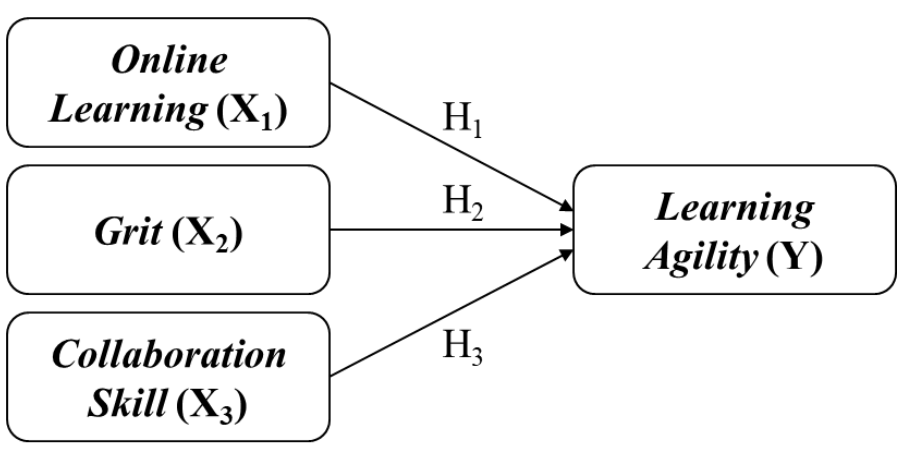

Gambar 1. Kerangka Berpikir

Dalam penelitian ini, hipotesis yang dirumuskan antara lain:

$\mathrm{H}_{1}$ : Terdapat pengaruh yang signifikan dari Online Learning terhadap Learning Agility

$\mathrm{H}_{2}$ : Terdapat pengaruh yang signifikan dari Grit terhadap Learning Agility

$\mathrm{H}_{3}$ : Terdapat pengaruh yang signifikan dari Collaborative Skill terhadap Learning Agility

\section{METODE}

Penelitian ini dilakukan dengan menggunakan metode kuantitatif berjenis asosiatif. Adapun data dikumpulkan melalui kuesioner yang disebarkan secara daring kepada para pegawai milenial yang 
bekerja di DKI Jaya. Adapun populasi yang diteliti adalah pegawai milenial DKI Jaya dengan kriteria: (1) termasuk golongan milenial (berusia 21-41 tahun/lahir pada tahun antara 1980-2000), (2) pegawai di DKI Jaya, dan (3) pernah menggunakan sistem online learning ketika bekerja. Metode penarikan sampel yang digunakan adalah purposive sampling dengan jumlah sampel yang didapatkan berjumlah 387 orang. Adapun metode analisis data yang digunakan adalah uji deskriptif, uji kualitas data mencakup uji validitas dan uji reliabilitas, uji beda, serta uji regresi linear sederhana dengan menggunakan SPSS 25 serta dibantu oleh program Microsoft Office Excel.

Data yang digunakan pada penelitian ini adalah data kuantitatif, yang bersumber dari data primer dan data sekunder. Adapun data primer diperoleh melalui pengisian kuesioner yang dibagikan kepada responden, yakni pegawai milenial DKI Jaya, sedangkan data sekunder diperoleh dari artikel, jurnal akademik, publikasi pemerintahan, sensus, statistik, dan lain-lain.

Definisi operasional dari masing-masing variabel yang akan diteliti:

\section{Variabel Dependen (Y)}

Variabel dependen dalam penelitian ini adalah Learning Agility. Learning agility adalah kemampuan individu untuk mempelajari kompetensi baru di bawah kondisi yang ia alami pertama kali, tangguh, dan berbeda yang ditunjukkan dengan kemampuan untuk belajar dengan orang lain, orientasi hasil, pemecahan masalah, dan suka bereksperimen. Menurut Gravett dan Caldwell (2016), terdapat 4 tipe dari learning agility yaitu; (1) Mental agility, (2) People agility, (3) Change agility, dan (4) Result agility.

\section{Variabel Independen (X)}

1. Online Learning $\left(\mathrm{X}_{1}\right)$

Online learning adalah suatu sistem pembelajaran yang menggunakan teknologi internet, mobile, maupun teknologi pendukung lainnya untuk menyelenggarakan proses pembelajaran, menciptakan konten baik yang berupa video, audio, maupun teks serta untuk mengatur pembelajaran secara menyeluruh dalam suatu organisasi. Menurut Teo (2010), terdapat 3 dimensi dari online learning, yakni: (1) Tutor Quality, (2) Perceived Usefulness, dan (3) Facilitating Conditions.

2. Grit $\left(\mathrm{X}_{2}\right)$

Grit adalah semangat dan ketekunan yang dilakukan untuk mencapai tujuan dan kesuksesan jangka panjang. Menurut Duckworth (2017), grit terbagi ke dalam 2 dimensi, yakni: (1) Consistency of Interest dan (2) Persistence of Effort.

3. Collaborative Skill $\left(\mathrm{X}_{3}\right)$

Collaborative skill adalah kemampuan individu untuk dapat bekerja sama dengan mengidentifikasi permasalahan yang ada, memberikan arahan dengan berkoordinasi dan berinteraksi secara kooperatif serta berkomunikasi dengan efektif untuk menemukan solusi dari permasalahan tersebut. Menurut Binkley, et al. (2011), terdapat 5 dimensi yang menjelaskan collaborative skill, 
yang ditunjukkan sebagai berikut: (1) Interact effectively with others, (2) Work effectively in diverse teams, (3) Manage projects, (4) Guide and lead others, dan (5) Be responsible to others.

\section{HASIL DAN DISKUSI}

\section{Profil Responden Penelitian}

Sebesar 63.92\% responden dalam penelitian ini lahir pada tahun 1994-2000 dan didominasi oleh responden berjenis kelamin perempuan sebesar 58.25\%. Penelitian ini didominasi oleh $69.07 \%$ responden lulusan S1. Berdasarkan domisili, sebesar 35.31\% responden berdomisili di Jakarta Barat dan $40.46 \%$ responden yang bekerja di institusi yang berlokasi di Jakarta Barat. Responden penelitian ini dominan bekerja di perusahaan swasta sebesar $76.03 \%$.

Validitas dan Reliabilitas Variabel

Tabel 1

Validitas dan Reliabilitas Variabel

\begin{tabular}{|c|c|c|c|}
\hline Variabel & Indikator & $\mathbf{R}_{\text {hitung }}$ & Cronbach's Alpha \\
\hline \multirow{12}{*}{ Learning Agility (Y) } & CA01 & 0.560 & \multirow{12}{*}{0.840} \\
\hline & CA02 & 0.616 & \\
\hline & CA03 & 0.616 & \\
\hline & MA01 & 0.619 & \\
\hline & MA02 & 0.627 & \\
\hline & MA03 & 0.547 & \\
\hline & PA01 & 0.635 & \\
\hline & PA02 & 0.622 & \\
\hline & PA03 & 0.548 & \\
\hline & RA01 & 0.566 & \\
\hline & RA02 & 0.599 & \\
\hline & RA03 & 0.665 & \\
\hline \multirow{8}{*}{ Online Learning $\left(\mathrm{X}_{1}\right)$} & TQ01 & 0.629 & \multirow{8}{*}{0.851} \\
\hline & TQ02 & 0.636 & \\
\hline & TQ03 & 0.678 & \\
\hline & TQ04 & 0.666 & \\
\hline & PU01 & 0.666 & \\
\hline & PU02 & 0.600 & \\
\hline & PU03 & 0.640 & \\
\hline & PU04 & 0.691 & \\
\hline
\end{tabular}




\begin{tabular}{|c|c|c|c|}
\hline & FC01 & 0.644 & \\
\hline & $\mathrm{FC} 02$ & 0.679 & \\
\hline \multirow{12}{*}{$\operatorname{Grit}\left(\mathrm{X}_{2}\right)$} & CI01 & 0.733 & \multirow{12}{*}{0.866} \\
\hline & CI02 & 0.758 & \\
\hline & CI03 & 0.775 & \\
\hline & CI04 & 0.746 & \\
\hline & CI05 & 0.747 & \\
\hline & CI06 & 0.744 & \\
\hline & PE01 & 0.521 & \\
\hline & PE02 & 0.491 & \\
\hline & PE03 & 0.480 & \\
\hline & PE04 & 0.514 & \\
\hline & PE05 & 0.521 & \\
\hline & PE06 & 0.479 & \\
\hline \multirow{17}{*}{$\begin{array}{c}\text { Collaborative Skill } \\
\qquad\left(\mathbf{X}_{3}\right)\end{array}$} & IS01 & 0.631 & \multirow{17}{*}{0.914} \\
\hline & IS02 & 0.651 & \\
\hline & IS03 & 0.523 & \\
\hline & IS04 & 0.665 & \\
\hline & WS01 & 0.641 & \\
\hline & WS02 & 0.601 & \\
\hline & WS03 & 0.687 & \\
\hline & WS04 & 0.680 & \\
\hline & WS05 & 0.694 & \\
\hline & MS01 & 0.671 & \\
\hline & MS02 & 0.656 & \\
\hline & MS03 & 0.660 & \\
\hline & GS01 & 0.683 & \\
\hline & GS02 & 0.626 & \\
\hline & GS03 & 0.634 & \\
\hline & GS04 & 0.656 & \\
\hline & BS01 & 0.677 & \\
\hline
\end{tabular}

Berdasarkan hasil pengujian pada tabel di atas, diketahui bahwa seluruh indikator variabel memiliki nilai validitas $\left(\mathrm{R}_{\text {hitung }}\right)$ yang lebih besar dari nilai $\mathrm{R}_{\text {tabel }}$ yaitu 0.0996 , maka seluruh indikator variabel dapat disimpulkan valid. Setelah pengujian validitas, peneliti melakukan uji reliabilitas dan diperoleh hasil nilai reliabilitas untuk masing-masing variabel bernilai lebih besar dari 0,7. Oleh karena itu, dapat disimpulkan bahwa variabel Learning Agility, Online Learning, Grit, dan Collaborative Skill reliabel. Maka, berdasarkan analisa validitas dan reliabilitas, dapat disimpulkan bahwa semua indikator tersebut valid dan dapat dipertahankan dalam model penelitian. Model penelitian dibangun oleh variabel valid-reliabel dan indikator yang valid.

\section{Analisa Deskriptif Variabel}

Di bawah ini merupakan hasil analisis statistik deskriptif dari keempat variabel yang dibahas dalam penelitian ini, yaitu: Learning Agility $(\mathrm{Y})$, Online Learning $\left(\mathrm{X}_{1}\right)$, Grit $\left(\mathrm{X}_{2}\right)$, dan Collaborative Skill $\left(\mathrm{X}_{3}\right)$. Berdasarkan jawaban responden terhadap butir pernyataan terkait dengan variabel yang diukur, maka dapat dihitung nilai rata-rata untuk setiap responden. Kemudian nilai rata-rata dari 
responden tersebut dirata-ratakan untuk setiap variabel, dimensi, dan indikator. Nilai rata-rata tersebut dapat dikelompokkan dalam lima kategori, yaitu sangat rendah, rendah, sedang, tinggi, dan sangat tinggi yang ditunjukkan dalam Tabel 3 di bawah ini.

Tabel 2

Interval Kategori

\begin{tabular}{|c|c|}
\hline Kategori & Keterangan \\
\hline $1.00-1.80$ & Sangat Rendah \\
\hline $1.81-2.60$ & Rendah \\
\hline $2.61-3.40$ & Sedang \\
\hline $3.41-4.20$ & Tinggi \\
\hline $4.21-5.00$ & Sangat Tinggi \\
\hline
\end{tabular}

Berdasarkan tabel interval kategori, kemudian nilai rata-rata setiap variabel, dimensi, dan indikator dapat diinterpretasikan dalam Tabel 4 di bawah ini.

Tabel 3

Analisa Deskriptif Variabel

\begin{tabular}{|c|c|c|c|}
\hline \multicolumn{2}{|c|}{ Variabel / Dimensi / Indikator } & Rerata & Kategori \\
\hline \multicolumn{1}{|c|}{ Learning Agility (Y) } & 3.87 & Tinggi \\
\hline & Change Agility & 3.85 & Tinggi \\
\hline & CA01 & 3.82 & Tinggi \\
\hline & CA02 & 3.81 & Tinggi \\
\hline & CA03tal Agility & 3.92 & Tinggi \\
\hline & MA01 & 3.89 & Tinggi \\
\hline & MA02 & 3.91 & Tinggi \\
\hline & MA03 & 3.91 & Tinggi \\
\hline & People Agility & 3.85 & Tinggi \\
\hline & PA01 & 3.88 & Tinggi \\
\hline & PA02 & 3.91 & Tinggi \\
\hline & PA03 & 3.88 & Tinggi \\
\hline & Result Agility & 3.83 & Tinggi \\
\hline & RA01 & 3.85 & Tinggi \\
\hline & RA02 & 3.86 & Tinggi \\
\hline & RA03 & 3.86 & Tinggi \\
\hline Online Learning & 3.83 & Tinggi \\
\hline & Tutor Quality & 3.86 & Tinggi \\
\hline & TQ01 & 3.87 & Tinggi \\
\hline & TQ02 & 3.85 & Tinggi \\
\hline & TQ03 & 3.88 & Tinggi \\
\hline & TQ04 & 3.86 & Tinggi \\
\hline & Perceived Usefulness & 3.83 & Tinggi \\
\hline & PU01 & 3.85 & Tinggi \\
\hline & PU02 & 3.83 & Tinggi \\
\hline & PU03 & 3.86 & Tinggi \\
\hline & PU04 & Tinggi \\
\hline
\end{tabular}




\begin{tabular}{|c|c|c|c|}
\hline & Facilitating Conditions & 3.88 & Tinggi \\
\hline & \begin{tabular}{l|l} 
FC01 \\
\end{tabular} & 3.90 & Tinggi \\
\hline & $\mathrm{FC02}$ & 3.86 & Tinggi \\
\hline \multicolumn{2}{|l|}{ Grit } & 3.64 & Tinggi \\
\hline & Consistency of Interest & 3.42 & Tinggi \\
\hline & \begin{tabular}{l|l} 
CI01 \\
\end{tabular} & 3.43 & Tinggi \\
\hline & $\mathrm{CI02}$ & 3.38 & Tinggi \\
\hline & $\mathrm{CI} 03$ & 3.47 & Tinggi \\
\hline & CI04 & 3.39 & Tinggi \\
\hline & $\mathrm{CI} 05$ & 3.43 & Tinggi \\
\hline & \begin{tabular}{l|l} 
& $\mathrm{CI} 06$ \\
\end{tabular} & 3.42 & Tinggi \\
\hline & Perseverance of Effort & 3.85 & Tinggi \\
\hline & \begin{tabular}{l|l} 
& PE01 \\
\end{tabular} & 3.79 & Tinggi \\
\hline & PE02 & 3.81 & Tinggi \\
\hline & PE03 & 3.96 & Tinggi \\
\hline & PE04 & 3.90 & Tinggi \\
\hline & PE05 & 3.87 & Tinggi \\
\hline & \begin{tabular}{l|l} 
PE06 \\
\end{tabular} & 3.77 & Tinggi \\
\hline \multicolumn{2}{|c|}{ Collaboration Skill } & 3.99 & Tinggi \\
\hline & Interact Effectively with Others & 3.98 & Tinggi \\
\hline & \begin{tabular}{l|l} 
IS01 \\
\end{tabular} & 3.99 & Tinggi \\
\hline & IS02 & 3.97 & Tinggi \\
\hline & IS03 & 3.97 & Tinggi \\
\hline & \begin{tabular}{l|l} 
& IS04 \\
\end{tabular} & 4.00 & Tinggi \\
\hline & Work Effectively with Diverse Team & 4.01 & Tinggi \\
\hline & \begin{tabular}{l|l} 
& WS01 \\
\end{tabular} & 3.99 & Tinggi \\
\hline & WS02 & 3.96 & Tinggi \\
\hline & WS03 & 4.05 & Tinggi \\
\hline & WS04 & 4.00 & Tinggi \\
\hline & \begin{tabular}{l|l} 
& WS05 \\
\end{tabular} & 4.05 & Tinggi \\
\hline & Manage Projects & 3.98 & Tinggi \\
\hline & \begin{tabular}{l|l} 
& MS01 \\
\end{tabular} & 3.98 & Tinggi \\
\hline & MS02 & 3.97 & Tinggi \\
\hline & \begin{tabular}{l|l} 
MS03 \\
\end{tabular} & 3.98 & Tinggi \\
\hline & Guide and Lead Others & 3.98 & Tinggi \\
\hline & \begin{tabular}{l|l} 
GS01 \\
\end{tabular} & 3.95 & Tinggi \\
\hline & GS02 & 3.98 & Tinggi \\
\hline & GS03 & 3.98 & Tinggi \\
\hline & \begin{tabular}{l|l} 
GS04 \\
\end{tabular} & 4.01 & Tinggi \\
\hline & Be Responsible to Others & 4.04 & Tinggi \\
\hline & \begin{tabular}{l|l} 
& BS01 \\
\end{tabular} & 4.04 & Tinggi \\
\hline
\end{tabular}

- Variabel Learning Agility

Pengukuran terhadap learning agility pada pegawai milenial DKI Jaya menunjukkan nilai rata-rata sebesar 3,87 seperti yang tertera pada Tabel 2. Bila ditelaah lebih rinci berdasarkan dimensinya, dapat dilihat bahwa tingkat learning agility tinggi pada dimensi change agility dengan nilai rata- 
rata sebesar 3,85; mental agility sebesar 3,89; people agility sebesar 3,88; dan result agility sebesar 3,85 .

\section{- Variabel Online Learning}

Pengukuran terhadap online learning pada pegawai milenial DKI Jaya menunjukkan nilai rata-rata sebesar 3,86 seperti yang tertera pada Tabel 2. Bila ditelaah lebih rinci berdasarkan dimensinya, dapat dilihat bahwa tingkat online learning tinggi pada dimensi tutor quality dengan nilai rata-rata sebesar 3,87; perceived usefulness sebesar 3,85; dan facilitating conditions sebesar 3.88 .

\section{- Variabel Grit}

Pengukuran terhadap grit pada pegawai milenial DKI Jaya menunjukkan nilai rata-rata 3,64 seperti yang tertera pada Tabel 2. Bila ditelaah lebih rinci berdasarkan dimensinya, dapat dilihat bahwa tingkat grit tinggi pada dimensi consistency of interest dengan nilai rata-rata sebesar 3,42 dan perseverance of effort sebesar 3,85 .

\section{- Variabel Collaborative Skill}

Pengukuran terhadap collaborative skill pada pegawai milenial DKI Jaya menunjukkan nilai ratarata 3,99 seperti yang tertera pada Tabel 2. Bila ditelaah lebih rinci berdasarkan dimensinya, dapat dilihat bahwa tingkat collaborative skill tinggi pada dimensi interact effectively with others dengan nilai rata-rata sebesar 3,98; work effectively with diverse team sebesar 4,01; manage projects sebesar 3,98; guide and lead others sebesar 3,98; dan be responsible to others sebesar 4,04.

\section{Uji Hipotesis}

\section{Tabel 4}

\section{Hasil Uji Hipotesis}

\begin{tabular}{|c|c|c|c|}
\hline Hipotesis & Uji Hipotesis & Sig & Kesimpulan \\
\hline Hipotesis 1 & Online Learning $\rightarrow$ Learning Agility & 0.000 & $\mathrm{H}_{0}$ ditolak \\
\hline Hipotesis 2 & Grit $\rightarrow$ Learning Agility & 0.557 & $\mathrm{H}_{0}$ diterima \\
\hline Hipotesis 3 & Collaborative Skill $\rightarrow$ Learning Agility & 0.000 & $\mathrm{H}_{0}$ ditolak \\
\hline
\end{tabular}

Hasil pengujian hipotesis menunjukkan bahwa:

- Hipotesis 1 dapat disimpulkan bahwa terdapat pengaruh signifikan dari Online Learning terhadap Learning Agility, maka $\mathrm{H}_{0}$ ditolak.

- Hipotesis 2 dapat disimpulkan bahwa tidak terdapat pengaruh signifikan dari Grit terhadap Learning Agility, maka $\mathrm{H}_{0}$ diterima.

- Hipotesis 3 dapat disimpulkan bahwa terdapat pengaruh signifikan dari Collaborative Skill terhadap Learning Agility, maka $\mathrm{H}_{0}$ ditolak.

\section{KESIMPULAN}

Penelitian ini bertujuan untuk melihat gambaran learning agility, online learning, grit, dan collaborative skill pada pegawai milenial DKI Jaya dan terdapat pengaruh yang signifikan dari 
masing-masing variabel independen, yakni online learning, grit, dan collaborative skill, terhadap learning agility pada pegawai milenial DKI Jaya. Adapun kesimpulan dari penelitian yang melibatkan 387 pegawai milenial DKI Jaya ini adalah bahwa pegawai milenial DKI Jaya menunjukkan skor yang tinggi pada masing-masing variabel. Hal tersebut dapat diinterpretasikan bahwa pegawai milenial DKI Jaya tangkas dalam belajar, terutama melalui daring, memiliki semangat dan ketekunan untuk mencapai tujuan pembelajaran dalam jangka panjang, serta mampu berkolaborasi untuk mencapai tujuan yang telah ditetapkan. Kemudian, online learning memiliki pengaruh positif secara signifikan terhadap learning agility pegawai milenial DKI Jaya, yang menunjukkan bahwa penggunaan online learning dapat memfasilitasi efektivitas learning agility dan penggunaan online learning memungkinkan para pegawai milenial DKI Jaya untuk berkinerja lebih baik dan meningkatkan learning agility mereka. Selanjutnya, collaborative skill memiliki pengaruh positif secara signifikan terhadap learning agility pegawai milenial DKI Jaya yang berarti bahwa penerapan collaborative skill diperlukan dan harus tercipta di lingkungan kerja untuk meningkatkan kemampuan learning agility pegawai. Namun, grit tidak berpengaruh secara signifikan terhadap learning agility pegawai milenial DKI Jaya. Maka untuk penelitian berikutnya, disarankan untuk menggunakan 8-item Grit-S untuk mengukur grit atau menggunakan salah satu dimensi dari Grit yaitu Perseverance of Effort dalam mengukur pengaruh terhadap learning agility.

\section{REFERENSI}

Aini, M., Narulita, E., \& Indrawati. (2020). 通过集成电路 3

学习模型增强创意思维和协作技巧 : 案例研究 Enhancing Creative Thinking and Collaboration

Skills through ILC3 Learning Model: A Case Study . Journal of Southwest Jiaotong University, 55(4), 1-11. https://doi.org/10.35741/issn.0258-2724.55.4.59

Aliyyah, I. H., \& Idham, R. A. (2020). Hubungan Learning Agility dan Perilaku Kolaborasi pada Pekerja di Jakarta. Biopsikososial, 179-198.

Basilaia, G., \& Kvavadze, D. (2020). Transition to Online Education in Schools during a SARSCoV-2 Coronavirus (COVID-19) Pandemic in Georgia. Pedagogical Research, 5(4).

https://doi.org/10.29333/pr/7937

Binkley, M., Erstad, O., Herman, J., Raizen, S., Ripley, M., Miller-Ricci, M., \& Rumble, M. (2011). Defining Twenty-First Century Skills. In Assessment and Teaching of 21st Century Skills (pp. 17-66). Springer Netherlands. https://doi.org/10.1007/978-94-007-2324-5_2

Budiati, I., Susianto, Y., Adi, W. P., Ayuni, S., Reagan, H. A., Larasaty, P., Setiyawati, N., Pratiwi, A. I., \& Saputri, V. G. (2018). Statistik Gender Tematik: Profil Generasi Milenial Indonesia (A. Said, I. Budiati, T. R. B. Rahayu, \& A. P. Raharjo, Eds.). Kementerian Pemberdayaan Perempuan dan Perlindungan Anak. 
Chen, Y., \& Lin, M. (2019). 大專運動代表隊恆毅力特質之探討 The Trait of Grit: A Study of College Athletes. 台灣管理學刊 Taiwan Academy of Management Journal, 19(1), 31-46. https://doi.org/10.6295/TAMJ.201902_19(1).0003

de Meuse, K. P., Dai, G., \& Hallenbeck, G. S. (2010). Learning agility: A construct whose time has come. Consulting Psychology Journal: Practice and Research, 62(2), 119-130. https://doi.org/10.1037/a0019988

Duckworth, A. (2016). Grit: The Power of Passion and Perseverance. Scribner.

Duckworth, A. (2017). Grit: The Power of Passion and Perseverance. Simon \& Schuster.

Duckworth, A. L., Peterson, C., Matthews, M. D., \& Kelly, D. R. (2007). Grit: Perseverance and passion for long-term goals. Journal of Personality and Social Psychology, 92(6), 1087-1101. https://doi.org/10.1037/0022-3514.92.6.1087

Ghosh, S., Muduli, A., \& Pingle, S. (2021). Role of e-learning technology and culture on learning agility: An empirical evidence. Human Systems Management, 40(2), 235-248. https://doi.org/10.3233/HSM-201028

Gravett, L. S., \& Caldwell, S. A. (2016). Learning Agility: The Impact on Recruitment and Retention. Palgrave Macmillan US. https://doi.org/10.1057/978-1-137-59965-0

Gray, B. (1989). Collaborating: Finding common ground for multi-party problems. Jossey-Bass. Hamid, A. (2020, October). Pengembangan Sumber Daya Manusia (SDM). https://bdkbanjarmasin.kemenag.go.id/berita/pengembangan-sumber-daya-manusia-sdm

Harman, B., \& Stein, S. (2015). The Art and Skill of Collaborative Leadership. Association for Talent Development.

Heiskala, M., Jokinen, J.-P., \& Tinnilä, M. (2016). Crowdsensing-based transportation services An analysis from business model and sustainability viewpoints. Research in Transportation Business \& Management, 18, 38-48. https://doi.org/10.1016/j.rtbm.2016.03.006

Husnussaadah. (2021). Strategi Pembelajaran E-learning di Era Digitalisasi. IQRA : Jurnal Pendidikan Agama Islam, 1(1), 10-16.

Imperatori, B. (2017). Engagement and Disengagement at Work. Springer International Publishing. https://doi.org/10.1007/978-3-319-51886-2

Michael M. Lombardo, \& Robert W. Eichinger. (2000). High potentials as high learners. Human Resource Management, 39(4), 321-329. https://doi.org/10.1002/1099-050X(200024)39:4<321::AIDHRM4>3.0.CO;2-1

MoLeNET. (2007). What is Online Learning? http://www.molenet.org.uk/

Noe, R. A. (2017). Employee Training \& Development (7th ed.). McGraw Hill Education.

O’Shea, T. (2016, August 3). Agility Winners Believe and Persevere. http://agilityconsulting.com/your-agility-advantage/agility-winners-believe-and-persevere/ 
Saputra, N., Abdinagoro, S. B., \& Kuncoro, E. A. (2018). The mediating role of learning agility on the relationship between work engagement and learning culture. Pertanika Journal of Social Science and Humanities, 26(S), 117-130.

Sudirgo, J. (2020, April 28). Pemimpin yang Super Agile di Tengah Situasi VUCA.

https://www.jimmysudirgo.com/post/pemimpin-yang-super-agile-di-tengah-vuca

Supiyanti, Y. (2019). Hubungan Learning Agility dengan Kemampuan Kolaborasi (Collaborative Skill) pada Pegawai di LIngkungan Lembaga Administrasi Negara.

Tang, Y., Zheng, J., Sun, X., \& Huang, Z. (2021).

协作能力：中国青少年社会与情感能力测评分报告之三 Collaboration: Report on the Study on

Social and Emotional Skills of Chinese Adolescence (III). 华东师范大学学报 Journal of East China Normal University, 39(9), 62-76. https://doi.org/10.16382/j.cnki.1000-5560.2021.09.004

Teo, T. (2010). Development and validation of the E-learning Acceptance Measure (ElAM). The Internet and Higher Education, 13(3), 148-152. https://doi.org/10.1016/j.iheduc.2010.02.001

Zhang, X., \& Jiang, B. (2019). 恒毅力养成 : 针对城市学龄前儿童的一种自然教育 Cultivation of Grit: A Type of Nature Education for Urban Preschool Children. 风景园林Landscape Architecture, 26(10), 40-47.

Zulfikar, A. (2019). SIKERJA, Tawaran bagi Pengembangan Ketenagakerjaan di Indonesia dalam Era VUCA. INA-Rxiv Papers. 